\title{
Modelling and simulation of de drive using PI and PID controller
}

\author{
Ms.Manjusha Patil \\ Lecturer, Electrical Engineering, GHRCEM, Pune, India
}

\begin{abstract}
Many industrial applications require high performance rotating electric drives. A proposed D C drive have a precise speed control, stable operation in complete range of speed and good transient behaviour with smooth and step less control. The purpose of developing a simulation using PI and PID control system is to get steady state and transient response of drive system. Once the type of controller has been decided then the design and analysis are done. This paper focuses modelling of separately excited DC motor for the analysis of machine under any condition and compares the step response of system with and without PI and PID controller.
\end{abstract}

Keywords: DC Motor, Modelling, Simulation, PI \& PID controller.

\section{INTRODUCTION}

Today, industries are increasingly demanding for process automation in all sectors such as defence, industries, Robotics etc. DC motors have been used in variable speed drives. The versatile control characteristics of dc motors have contributed to their extensive use in industry. DC drives are less complex with a single power conversion from AC to DC. DC drives are normally less expensive for most horsepower ratings. DC motors have a long tradition of use as adjustable speed machines and a wide range of options have evolved for this purpose. The objective of this paper is modelling of $\mathrm{D} C$ motor to get transfer function to form closed loop control system with PI and PID controller with their step response in MATLAB/ Simulink for separately excited D C motor.

\section{MODELLING}

\section{A .Model of D C separately excited motor}

A DC motor can be seen to be comprised of three main parts: current carrying conductors called an armature; a circuit for magnetic field provided by magnets of poles; and a commutator that switches the direction of current in the armature as it passes a fixed point in space.

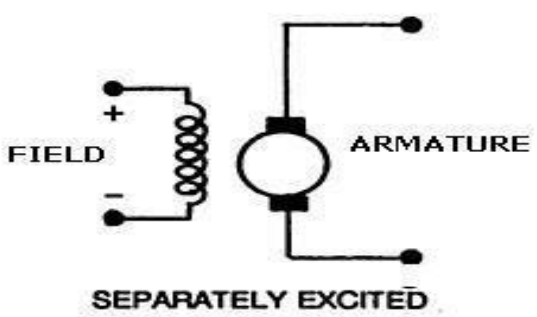

Fif.1 Symbol of DC Separately excited motor
In order to build the DC motors transfer function its simplified mathematical model has been used. The current in the field coil and armature coil independent of one another. As a result these motor have excellent speed and torque control. The equation describing the dynamic behaviour of DC motor is as follows.

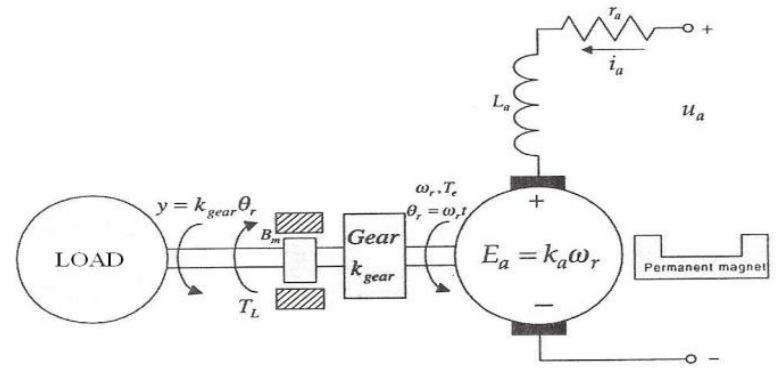

Fig. 2 Free Body Diagram of Rotor

Here,

$\mathrm{Va}=$ Armature Voltage in volt

$\mathrm{Ra}=$ Armature Resistance in Ohm

$\mathrm{La}=$ Armature Inductance in Henry

$\mathrm{Ia}=$ Armature Current in Amp

$\mathrm{Eb}=\mathrm{Back} \mathrm{EMF}$ in Volt

$\mathrm{Tm}=$ Mechanical Torque in N-m

$\mathrm{J}=$ Moment of Inertia $\mathrm{Kg}-\mathrm{m}^{2}$

$\mathrm{B}=$ Damping Coefficient Nm.Sec

If = Field Current in Amp

$\mathrm{Lf}=$ Field Inductance in Henry

$\mathrm{Vf}=$ Field Voltage in Volt

The motor torque $\mathrm{Tm}$ is related to the armature current, i, by constant factor $\mathrm{Kt}$ by constant rotational speed by following equation,

$\mathrm{T}_{\mathrm{m}}=\mathrm{K}_{\mathrm{t}} \mathrm{i}$

$\mathrm{e}_{\mathrm{m}}=\mathrm{K}_{\mathrm{E}} \dot{\theta}$

As per Newton's Law combined with Kirchhoff's Law:

$$
\mathrm{J} \theta+\mathrm{b} \dot{\theta}=\mathrm{K}_{\mathrm{m}} \mathrm{i}-\mathrm{T}_{\mathrm{L}}
$$

$\mathrm{L}_{\mathrm{m}} \frac{\mathrm{di}}{\mathrm{dt}}+\mathrm{R}_{\mathrm{m}} \mathrm{i}=\mathrm{V}-\mathrm{K}_{\mathrm{M}} \dot{\theta}$

Using Laplace Transforms, the above equation can be expressed in terms

$$
\begin{aligned}
& S(J s+b) \theta(s)=K_{m} I(s)-T_{L}(s) \\
& \left(L_{m} s+R_{m}\right) I(s)=V(s)-K_{m} s \ddot{\theta}
\end{aligned}
$$


By eliminating I(s), the following open -loop transfer A small error at time 10 has an importance of 10 times function can be obtained, where rotational speed is the error. In this manner, integral increases the response of the output and voltage $\mathrm{V}$ in input system to a given error over time until it is corrected. In electric drive system, it is desired to describe the Integral can also be adjusted and the adjustment is called appropriate transfer function of motor between motor the reset rate. Reset rate is a time factor. The shorter the voltage and its speed.

For this purpose assuming Load torque $\mathrm{TL}=0$,

And friction torque $\mathrm{Tf}=0$, since neither affects the transfer function

Therefore

$$
\left.\frac{\dot{\theta}(\mathrm{s})}{\mathrm{V}(\mathrm{s})}\right|_{\mathrm{T}_{\mathrm{L}}(\mathrm{s})=0}=\frac{\mathrm{K}_{\mathrm{m}}}{(\mathrm{J} \mathrm{s}+\mathrm{b})\left(\mathrm{L}_{\mathrm{m}} \mathrm{s}+\mathrm{R}_{\mathrm{m}}\right)+\mathrm{K}_{\mathrm{m}}^{2}}
$$

State-Space Representation:

In state space form eqn.3, 4 can be expressed by choosing rotational speed and current as the state variable and voltage is input

$$
\begin{aligned}
& \frac{\mathrm{d}}{\mathrm{dt}}\left[\begin{array}{c}
\dot{\theta} \\
i
\end{array}\right]=\left[\begin{array}{cc}
-\frac{\mathrm{b}}{\mathrm{J}} & \frac{\mathrm{K}_{\mathrm{m}}}{\mathrm{J}} \\
-\frac{\mathrm{K}_{\mathrm{m}}}{\mathrm{L}_{\mathrm{m}}} & -\frac{\mathrm{R}_{\mathrm{m}}}{\mathrm{L}_{\mathrm{m}}}
\end{array}\right]\left[\begin{array}{c}
\dot{\theta} \\
\mathrm{i}
\end{array}\right]+\left[\begin{array}{c}
0 \\
\frac{1}{\mathrm{~L}_{\mathrm{m}}}
\end{array}\right] \mathrm{V} \\
& \dot{\theta}=\left[\begin{array}{ll}
1 & 0
\end{array}\right]\left[\begin{array}{c}
\dot{\theta} \\
i
\end{array}\right]
\end{aligned}
$$

\section{B. Selection of motor parameters}

The DC motor under study has the following specification and parameters.

1. Specifications:

3hp, 230V,11Amp, $1500 \mathrm{rpm}$

2. Parameters:

$\mathrm{Ra}=2.45 \mathrm{ohm}, \mathrm{La}=0.2145 \mathrm{H}, \mathrm{Kb}=1.05 \mathrm{volt} / \mathrm{rad} / \mathrm{sec}, \quad \mathrm{J}=5 \mathrm{~kg}-$ $\mathrm{m} 2, \mathrm{~B}=0.0859 \mathrm{~N} / \mathrm{rad} / \mathrm{sec}$.

\section{Control System Design}

Types of controller

\section{A-Proportional Control:}

In proportional controller it examines the magnitude of the error and it reacts proportionally. A large error receives a large response. For example, if there is a large temperature error, the fuel valve would be opened a lot. On the other hand, a small error receives a small response. In mathematical term, the proportional term (Pout) is expressed as:

Pout $=\mathrm{Kp}^{* \mathrm{e}}$

Where:

Pout: Proportional portion of controller output

$\mathrm{Kp}$ : Proportional gain

e : Error signal,

$\mathrm{e}=$ Set-point - Process Variable

\section{2- Integral Control:}

The integral type of controller overcomes the offset, integral control attempts to correct small error (offset). Integral examines the error over time and increases the importance of even a small error over time. Integral is equal to error multiplied by the time the error has persisted. A small error at time zero has zero importance. reset rate the quicker the correction of an error. However, too short a reset rate can cause erratic performance. In hardware-based systems, the adjustment can be done by a potentiometer changing the time constant of a $\mathrm{RC}$ circuit. Most of today's applications use software based control such as

Where:

$$
\mathrm{I}_{\text {out }}=\frac{1}{\mathrm{~T}_{\mathrm{i}}} \int \text { edt }=\mathrm{K}_{\mathrm{i}} \int \text { edt }
$$

Iout: Integral portion of controller output

Ti: Integral time, or reset time

$\mathrm{Ki}$ : Integral gain

e : Error signal, e = Set-point - Process Variable

\section{3-Derivative Control:}

The derivative controller gives the control output with the rate of change in the error signal. Derivative will cause a greater system response to a rapid rate of change than to a small rate of change. In other words, if a system's error continues to rise, the controller must not be responding with sufficient correction. Derivative senses this rate of change in the error and provides a greater response. Derivative is adjusted as a time factor and therefore is also called rate time. It is essential that too much derivative should not be applied or it can cause overshoot or erratic control. In mathematical term, the derivative term (Dout) is expressed as:

Where:

$$
D_{\text {out }}=T_{d} \frac{d}{d t} e=K_{d} \frac{d}{d t} e
$$

Dout: Derivative portion of controller output

Td: Derivative time

$\mathrm{Kd}$ : Derivative gain

e : Error signal, e = Set-point - Process Variable

\section{4- PID controller:}

PID controllers typically use control loop feedback in industrial and control systems applications. The controller first computes a value of error as the difference between a measured process variable and preferred set-point. It then tries to minimize the error by increasing or decreasing the control inputs to the process, so that process variable moves closer to the set point. This method is most useful when a mathematical model of the process or control is too complicated or unknown.

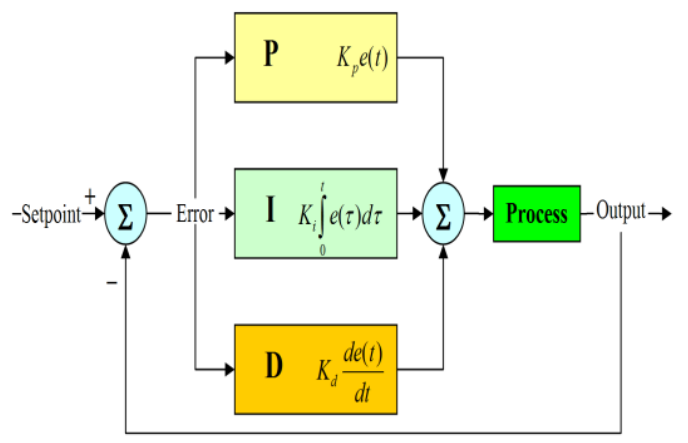

Fig.3 PID controller block diagram 
To design steady state system and improve step response of PID controller proper tuning constant have to done.

Obtaining any open loop response and determining what need to be improved.

$>\quad$ Kp to improve the rise time.

$>\quad$ Kd to improve the overshoot.

$>\quad \mathrm{Ki}$ to eliminate the steady state error.

tune each of $\mathrm{Kp}, \mathrm{Kd}, \mathrm{Ki}$ constant until obtaining a desired response.

\section{IV.SELECTION OF CONTROLLER}

The control system be analyzed and suitable controller be selected and design Listed below are the most important properties of the widely used P, PI, PID

a. Whether the system is based on integral or proportional control action.

b. Process lag.

c. Speed of the error correction.

d. Acceptability of steady-state error.

According to the above table, controllers and systems can be assigned to each other as:

$>\quad$ For easy-to-control systems where steady-state errors are acceptable, $\mathrm{P}$ controllers are used.

$>\quad$ In systems with great lag where offset is tolerable PD controllers are used

$>\quad$ For applications with low requirement to control dynamics and where the system does not exhibits great lags, I controllers are used

$>$ For a dynamic control response without exhibiting the steady state error, PI controllers are used

$>\quad$ If it is required that the speed of the response is as high as possible, regardless of the

Greater lag, PID controllers are used.

\section{Simulation}

By implementing simulating model in MATLAB/simulink the response of the open and close loop system with and without controller can study and compare the performance.

\section{D C drive without controller}

In first simulation all parameters of motor refer and connect the system in open loop i.e without feedback and on scope we get the step response for open loop controller.

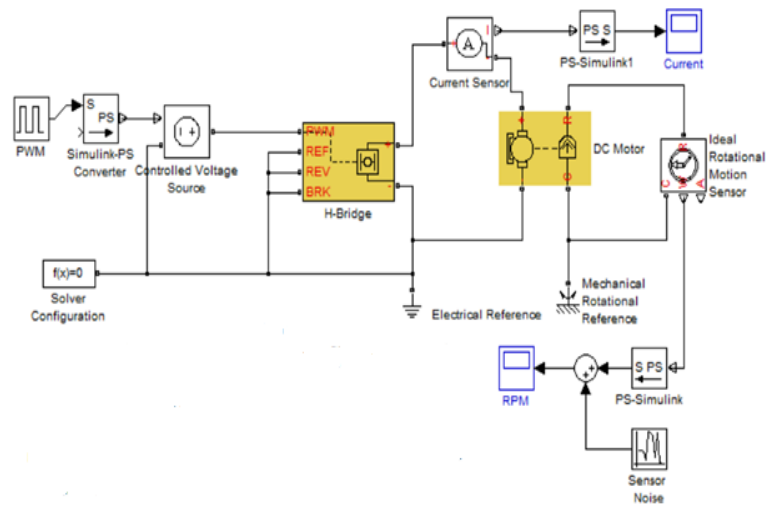

Fig.4 Block Diagram of open loop system

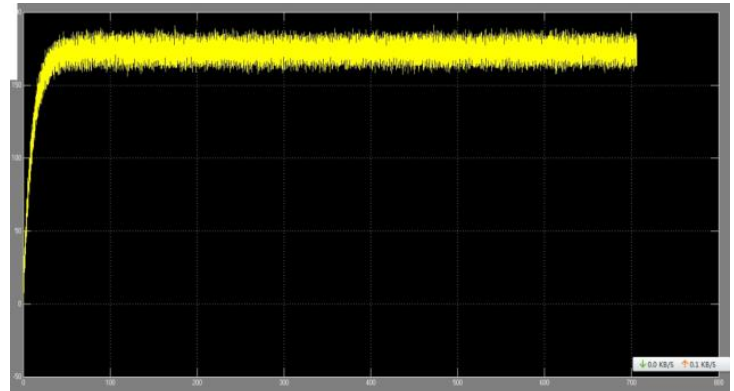

Fig.5 Step response of system without controller

\section{D.C drive with PI controller}

In second simulation PI controller to control the $\mathrm{d} c$ motor. We form closed loop system by adding the speed sensor and converting analog to digital using Ato D conversion block. Basically we implement the Phase lock loop for $\mathrm{d} \mathrm{c}$ motor as follows.

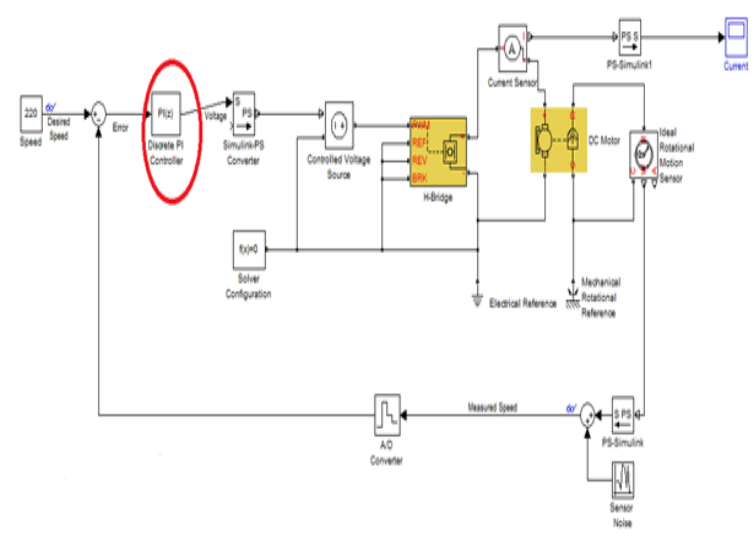

Fig.6 Block Diagram of closed loop system with PI controller

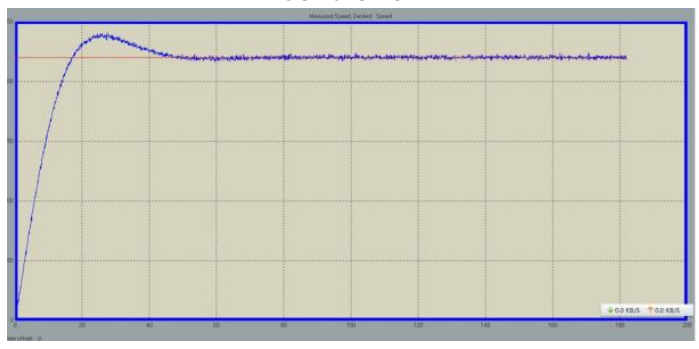

Fig.7 Step response of system with PI controller

3 .D.C drive with PID controller:

In third simulation we replace PI controller by discrete type PID controller. And get the step response for $\mathrm{d} \mathrm{c}$ drive

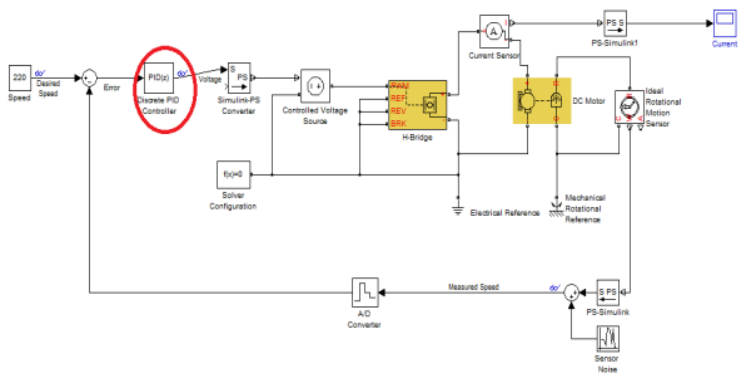

Fig.8 Block Diagram of closed loop system with PID 


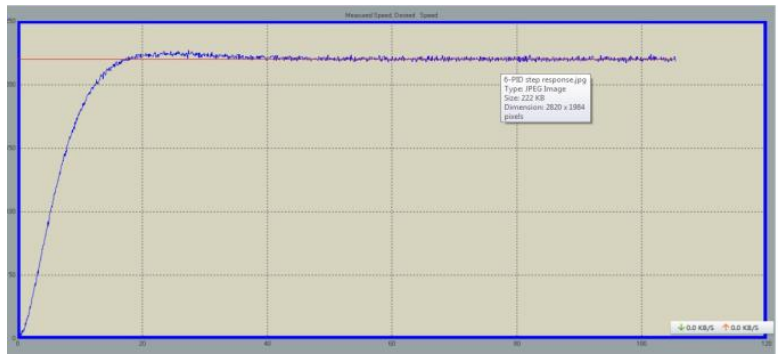

Fig.7 Step response of system with PID controller

\begin{tabular}{|l|l|l|}
\hline PARAMETER & PI & PID \\
\hline STEADY STATE ERROR & LESS & LESS \\
\hline SETTELING TIME & $25 \mathrm{sec}$ & $20 \mathrm{sec}$ \\
\hline OVERSHOOT & HIGH & LESS \\
\hline RISE TIME & $15.4 \mathrm{sec}$ & $13.2 \mathrm{sec}$ \\
\hline STEP RESPONSE & STABLE & MORE STABLE \\
& & \\
\hline
\end{tabular}

Table.1 Comparisons of step response PI and PID

\section{VI.CONCLUSION}

The proportional - integral - derivative (PID) controller operates the majority of the control system in the world. It has been reported that more than $95 \%$ of the controllers in the industrial process control applications are of PID type as no other controller match the simplicity, clear functionality, applicability and ease of use offered by the PID controller. PID controllers provide robust and reliable performance for most systems if the PID parameters are tuned properly.

\section{REFERENCES}

[1] Power Electronics by M.D.Singh and K.D. Khanchandani

[2] Wikipedia - PID controller

[3] I.J.Nagrath and M.Gopal, Control Systems Engineering, (Wiley Eastern Limited).

[4] William Palm III, Modelling, Analysis and Control of Dynamic Systems, 2nd edition, John Wiley and Sons.

[5] ]M. H. Rashid, Power Electronics, Circuits Devices and Applications,2nd Edition, Prentice- Hall International, Inc., New Jersey, 1993

[6] W. P. Aung," Analysis on Modeling and Simulink of DC Motor and its Driving System Used for

[7] Wheeled Mobile Robot", World Academy of Science, Engineering and Technology 32, 2007, pp.299-306.

[8] B. Kuo, Automatic Control Systems, Prentice-Hall, Englewood, Cliffs. NJ, 1995.

[9] N. S. Nise, Control Systems Engineering (3rd Edition), John Wiley and Sons Inc., New York, 2000.

[10] A. Klee, Development of a Motor Speed Control System Using MATLAB and Simulink,Implemented with a Digital Signal Processor, MSc. Thesis, Orland, Florida, 2005.

[11] Dr. Jamal A. Mohammed Modelling, Analysis and Speed Control Design Methods of

[12] a DC Motor, * Eng. \& Tech. Journal, Vol. 29, No. 1, 2011 